\title{
Agenda Ambiental na UNICENTRO: um estudo da qualidade de vida no trabalho a partir do método Kruger
}

Revista Brasileira de Tecnologias Sociais
${ }^{1}$ Unicentro, Guarapuava, Paraná, Brasil, $\quad$ acpires@unicentro. edu.br. Mestre em Gestão de Políticas Públicas pela Univali, Itajaí, SC. Técnico em Assuntos Universitários na Universidade do Centro-Oeste (UNICENTRO).

${ }^{2}$ Universidade do Vale do Itajaí, Programa de Mestrado em Gestão de Políticas Públicas, Itajaí, SC, Brasil, carlosinterligado@yahoo. com.br. Dr. em Comunicação Social pela PUCRS. Professor no Mestrado em Gestão de Políticas Públicas da UNIVALI, Itajaí, SC.

\section{Environmental Agenda at UNICENTRO: a study of quality of life in the workplace, based on the Kruger method}

\author{
Antonio Carlos Pires de Lima ${ }^{1}$; Carlos Golembiewsit ${ }^{2}$
}

Resumo: Este artigo apresenta um diagnóstico das ações ambientais realizadas pela Unicentro, visando à implantação de uma Agenda Ambiental. O estudo faz parte da Dissertação de Mestrado apresentada no Programa de Pós-Graduação em Gestão de Políticas Públicas da UNIVALI. Por questões de espaço, apresenta-se aqui apenas a análise referente à qualidade de vida no ambiente de trabalho. O referencial teórico é formado pelos conceitos de Sustentabilidade e Agenda Ambiental na Administração Pública. Em relação aos resultados, conclui-se que a universidade ainda precisa melhorar muito as suas ações, para que possa ter efetivamente uma Agenda Ambiental implantada.

Abstract: This article presents a diagnosis of the environmental actions undertaken by Unicentro, aimed at implementing an Environmental Agenda. The study is part of a Master's degree thesis submitted as part of the Postgraduate Program in Management of Public Policies, of UNIVALI. Due to space constraints, we present here only the analysis of quality of life in the workplace. The theoretical framework is composed of the concepts of Sustainability and Environmental Agenda in Public Administration. In relation to the results, it is concluded that the university still needs to improve its actions considerably, in order to effectively implement an environmental agenda. 


\section{INTRODUÇÃO}

A necessidade de um diagnóstico das condições institucionais para a proposta de uma Agenda Ambiental para a Universidade do Centro-Oeste do Paraná (UNICENTRO) surgiu da convivência, como funcionário da instituição, e da observação de que apenas algumas ações são percebidas no que diz respeito à busca da preservação do Meio Ambiente. Cabe ressaltar que a universidade desempenha um papel social relevante na sociedade brasileira, não somente na oferta de cursos, mas também no sentido de desenvolver experiências que podem ser incorporadas à sociedade.

No Brasil, a universidade é identificada como a instituição responsável pela “[ ...] criação do conhecimento novo e a disseminação desse conhecimento, através do ensino e da extensão" (FÁVERO, 1988, p. 46). Essa perspectiva tem sua importância no que se refere à questão ambiental, porque os novos conhecimentos incorporam aspectos relacionados à Sustentabilidade e à Preservação Ambiental, permitindo que a sociedade tenha uma noção melhor acerca desses objetivos.

Este artigo faz um diagnóstico para implantação de uma Agenda Ambiental na UNICENTRO, cuja sede fica no município de Guarapuava. Como esta pesquisa foi apresentada originalmente numa dissertação de Mestrado, optou-se, por uma questão de espaço, apresentar apenas os resultados referentes à Qualidade de Vida no ambiente de trabalho. Para compreensão do tema, o referencial teórico é formado pelo conceito de Sustentabilidade e Agenda Ambiental na Administração Pública.

\section{SUSTENTABILIDADE}

Para as instituições públicas, a Sustentabilidade é um processo de transformação, pelo fato de representar o atendimento a uma nova meta: a Preservação Ambiental. Essa condição indica que sua atuação deve ser movida pelo reconhecimento do seu "[ ...] papel estratégico na indução de novos referenciais de produção e consumo, orientados para a sustentabilidade” (BRASIL, 2013, p. 10).

A influência das instituições públicas no meio social é significativa, situação que as torna referência no uso da Sustentabilidade nas suas atividades e na conduta de seus agentes. A prática de ações sustentáveis pelos órgãos públicos reforça o comprometimento com o interesse público para minimizar o impacto das atividades no Meio Ambiente, além de demonstrar um nível de consciência ambiental significativo, passível de ser identificado pela sociedade (SCHNEIDER, 2013).

As atividades estatais não podem mais se desvincular da proteção ao Meio Ambiente, porque o exercício de uma postura de respeito ambiental é uma responsabilidade de toda a sociedade (VAZ et al., 2010). Nesse contexto, cabe aos órgãos estatais cultivarem essa posição como forma de evidenciar seu comprometimento com a causa ambiental, como também servir de exemplo à sociedade, estimulando-a a seguir a mesma conduta (BRASIL, 2013).

As ações que envolvem o comportamento dos agentes públicos indicam a percepção do significado da Sustentabilidade, no sentido de proporcionar a adequação das atividades à legislação ambiental vigente. Essa postura é determinante para que os órgãos públicos possam exercer sua Responsabilidade Ambiental de maneira plena, estabelecendo práticas e ações que sejam "ambientalmente corretas". O termo reforça que não há como praticar a Sustentabilidade sem que haja modificação de hábitos e condutas, principalmente quando estas podem produzir efeitos significativos no Meio Ambiente, como ocorre com a produção de lixo (MACHADO, 2012).

Lima, A.C.P; Golembiewsk, C. 
Responsabilidade Ambiental é um conjunto de atitudes, individuais ou empresariais, voltadas para o desenvolvimento sustentável do planeta. Ou seja, essas atitudes devem levar em conta o crescimento econômico ajustado à proteção do Meio Ambiente, na atualidade e para as gerações futuras, garantindo a sustentabilidade (SUAPESQUISA, 2014).

A legislação procura adequar as atividades públicas à Preservação Ambiental, mas há a possibilidade de ir além do que as normas determinam, condição que revela o compromisso dos órgãos públicos com o Meio Ambiente (GOLDONI, 2013). Além da legislação, há, também, a possibilidade de se implantar Agendas Ambientais, como a Agenda Ambiental na Administração Pública, que permite o acesso a critérios e a diretrizes que possam modificar condutas e garantir a Sustentabilidade dos seus negócios.

\section{Agenda Ambiental na Administração Pública}

A Agenda Ambiental é um tipo de plano adequado à implantação de ações que contemplem a Sustentabilidade, visando estabelecer práticas e condutas que sejam ambientalmente adequadas ao propósito da Preservação Ambiental. Campos (2013, p. 3) lembra que a Agenda Ambiental “[...] é um plano de desenvolvimento e interação que diagnostica e propõe soluções para uma população ou grupo reduzir os impactos negativos que suas intervenções causam no Meio Ambiente”.

Para Goldoni (2013) e Ferreira (2012), uma Agenda é composta pelos seguintes elementos: diagnóstico, levantamento de propostas, criação do plano de ação, acompanhamento e avaliação e revisão anual. Tais fatores são fundamentais para que, com a Agenda Ambiental instituída, torne-se possível que a Responsabilidade Ambiental seja praticada pela organização, estabelecido um comprometimento com a Preservação Ambiental e com a Sustentabilidade. No setor público do Brasil, foi criada em 1999 a Agenda Ambiental na Administração Pública (A3P), que representa:

[...] o principal programa da administração pública de gestão socioambiental. Visa implementar iniciativas específicas e desenvolver projetos e programas que promovam a discussão sobre desenvolvimento e a adoção de uma política de responsabilidade socioambiental no setor público. (BRASIL, 2013, p. 4).

Nas universidades, a Agenda Ambiental pode ser incorporada. Ela permite que a instituição alcance resultados e, sobretudo, consiga administrar suas atividades dentro do viés da Sustentabilidade e, desse modo, obtenha resultados importantes, que não se resumam a colaborar para a questão ambiental, mas que possam influenciar positivamente nos resultados de suas atividades. Uma das metas da Agenda é conseguir evitar o desperdício, um dos principais problemas que causa danos ao Meio Ambiente do país (Brasil, 2013). De acordo com Engelman, Guisso e Fracasso (2009, p. 23), essa agenda contempla:

[...] a demanda por uma gestão integrada capaz de evitar e solucionar conflitos e de promover a organização de um processo cooperativo que estimule diversos atores sociais à participação, à cooperação e à comunicação na superação de uma visão utilitarista, que concebe o meio ambiente apenas como provedor de recursos naturais. As instituições educacionais têm um papel fundamental em relação à sustentabilidade e por isso, seus processos e serviços devem levar em consideração os níveis: individual, organizacional, político-econômico, sociocultural e ecológico. 
As universidades podem fortalecer o alcance da Sustentabilidade nas organizações, efetivando sua função educativa, não somente junto aos acadêmicos, mas também contemplando a sociedade em que está inserida. Essa condição decorre do reconhecimento de que a universidade é uma instituição com condições de compartilhar suas experiências com a comunidade, contribuindo para que esta possa atingir um nível melhor de Sustentabilidade e comprometimento com a causa ambiental.

\section{Participantes da Pesquisa}

Durante a coleta de dados foram consultados os respectivos coordenadores de cada área na UNICENTRO, que estão envolvidos com os fatores de gestão ambiental destacados no protocolo. Nos itens "qualidade de vida no trabalho" e "sensibilização e capacitação dos servidores", foi consultada a Pró-Reitora de Recursos Humanos; e, para o item "licitações sustentáveis”, foi ouvido o Diretor de Compras da instituição.

Com a intenção de atender ao princípio ético do sigilo, preceituado pela Resolução CNS 196/1996, que trata de pesquisa envolvendo a participação de pessoas, seus nomes foram excluídos, sendo identificados apenas os cargos que exercem na instituição:

- Diretoria de Campus: DIRETOR A;

- Área Pedagógica: DOCENTE A;

- Diretoria de Pró Reitoria de Recursos Humanos: DIRETOR B;

- Diretoria de Compras e Materiais: DIRETOR C.

Contudo, na análise dos eixos temáticos da $\mathrm{A} 3 \mathrm{P}$ houve a inclusão do diretor do Campus Santa Cruz da UNICENTRO que, por motivos particulares, não participou da primeira etapa da pesquisa que envolveu a participação e o preenchimento de um questionário, sendo denominado DIRETOR D. Este questionário teve como objetivo buscar mais informações sobre a forma que o Meio Ambiente é tratado e abordado na UNICENTRO. Com o intuito de reforçar as discussões, foram utilizados estes dois instrumentos, sendo um questionário e o Método Kruger. Para o processo de análise e discussão do tema, houve a opção em destacar a posição dos participantes da pesquisa a partir das diretrizes constantes na $\mathrm{A} 3 \mathrm{P}$ e nos autores que abordam o tema.

\section{Qualidade de Vida no Ambiente de Trabalho}

A inclusão da Qualidade de Vida no Trabalho (QVT) na A3P revela que essa Agenda tem um comprometimento significativo com o ser humano, não atrelando seu foco à temática ambiental, mas procurando valorizar as pessoas, como promotoras das ações, que contribuirão para a minimização dos impactos das atividades desenvolvidas pela instituição no Meio Ambiente.

De acordo com a Agenda Ambiental, a QVT é um compromisso da Administração Pública com seus servidores, ao pactuarem uma relação de respeito entre as instituições públicas e as pessoas que atuam em suas estruturas organizacionais. Nesse sentido, cabe ressaltar que:

A administração pública deve buscar permanentemente uma melhor Qualidade de Vida no Trabalho promovendo ações para o desenvolvimento pessoal e 
profissional de seus servidores. Para tanto, as instituições públicas devem desenvolver e implantar programas específicos que envolvam o grau de satisfação da pessoa com o ambiente de trabalho, melhoramento das condições ambientais gerais, promoção da saúde e segurança, integração social e desenvolvimento das capacidades humanas, entre outros fatores. (BRASIL, 2012, 43).

A busca permanente pela melhor QVT possível para o servidor evidencia um compromisso significativo da instituição com o bem-estar humano, fazendo com que a atenção que dispensa ao Meio Ambiente seja um desdobramento dessa proposta, posto que esse meio influi diretamente na qualidade das pessoas.

Outro aspecto a ser considerado é que o ser humano passa a maior parte do seu tempo do dia no ambiente de trabalho, condição que ratifica a relevância da QVT, portanto, precisa preservar seu bem-estar, sentindo-se motivado para o exercício de suas funções, colaborando, assim, para que a instituição concretize seus objetivos, incluindo as propostas que tratam da preservação ambiental. Oliveira et al. (2014, p. 3) pontuam que a instituição que desenvolve a QVT evidencia o seu compromisso com o “[...] bem-estar dos funcionários, pois estes deixam de ser apenas trabalhadores tornando-se elementos estratégicos por excelência, e assim, seu desempenho torna-se parte inerente ao desenvolvimento e competitividade da organização".

Na esfera da Sustentabilidade, a QVT revela-se como uma prática de gestão de recursos humanos pautada na valorização do ser humano, dando oportunidade para que a instituição se mobilize a fim de atender as necessidades e os anseios do servidor. Com isso, pode favorecer o estabelecimento de uma relação mais dinâmica e, também, contribuir para que este possa desempenhar suas atividades em um ambiente seguro e compatível com o esforço que elas exigem, minimizando os riscos à sua integridade, à dignidade e à saúde. A QVT, no âmbito da Sustentabilidade, torna-se, segundo Silva, Longo e Quelhas (2010, p. $83)$ :

[...] a condição de trabalho que fornece qualidade de vida sustentável, considerando os aspectos relacionados à segurança econômica, ao bem-estar social e à qualidade ambiental, definidos pelos valores das pessoas envolvidas ou afetadas.

Quando incorporada à Sustentabilidade, a QVT favorece a conciliação entre os interesses dos servidores e os da instituição, promovendo um nível maior de satisfação que contribui para que eles desempenhem suas funções de forma segura e compatível com suas particularidades, bem como a possibilidade de desenvolverem um nível de comprometimento com os objetivos, as metas e os projetos que a organização desenvolve.

Em relação à pesquisa realizada, o protocolo de Krüger et al. (2011) é abrangente, sendo que, na análise das respostas concedidas pelo DIRETOR B, optou-se por dividir as questões em quatro segmentos, que são: condições ambientais, atenção à saúde, desenvolvimento/capacitação e integração no ambiente de trabalho.

Nas condições ambientais, o DIRETOR B elencou as seguintes situações: 
Quadro 1 - Condições ambientais na UNICENTRO

\begin{tabular}{|c|c|c|c|}
\hline QUESTÃO & $\begin{array}{l}\text { CONDIÇÃO } \\
\text { EXISTENTE } \\
\end{array}$ & MOTIVO & $\begin{array}{c}\text { CONSIDERAÇÕES DO } \\
\text { DIRETOR B }\end{array}$ \\
\hline $\begin{array}{l}\text { A UNICENTRO atende } \\
\text { a todas as exigências de } \\
\text { acessibilidade em todas as } \\
\text { suas instalações? }\end{array}$ & Atende & $\begin{array}{c}\text { A necessidade de facilitar } \\
\text { o acesso a todas as } \\
\text { dependências e a tudo que a } \\
\text { universidade oferece a toda } \\
\text { a comunidade acadêmica } \\
\text { independente de suas } \\
\text { dificuldades. }\end{array}$ & $\begin{array}{c}\text { "Possui elevadores, rampas } \\
\text { de acesso e sinalizações. Falta } \\
\text { avançar no que diz respeito à } \\
\text { deficiência visual, atualmente } \\
\text { os softwares não estão prontos } \\
\text { para acesso dos deficientes } \\
\text { visuais". }\end{array}$ \\
\hline $\begin{array}{l}\text { A UNICENTRO possui } \\
\text { preocupação com a } \\
\text { ergonomia de mobiliários e } \\
\text { os equipamentos de uso dos } \\
\text { servidores e bolsistas? }\end{array}$ & Possui & $\begin{array}{c}\text { Mudança de infraestrutura } \\
\text { e o programa de atenção } \\
\text { à saúde já prevê esta } \\
\text { preocupação no que diz } \\
\text { respeito à ergonomia. }\end{array}$ & $\begin{array}{l}\text { "O mapeamento já foi iniciado } \\
\text { de forma ainda tímida pela } \\
\text { Pró-Reitoria de Recursos } \\
\text { Humanos juntamente com a } \\
\text { Pró- Reitoria de Planejamento } \\
\text { e todos os setores da } \\
\text { universidade. Serão mapeados } \\
\text { riscos físicos, biológicos e } \\
\text { químicos de cada um dos } \\
\text { ambientes. Logicamente, entre } \\
\text { mapear e mudar existe um } \\
\text { passo grande, pois depende da } \\
\text { adaptação e reformulação da } \\
\text { estrutura física existente". } \\
\end{array}$ \\
\hline $\begin{array}{l}\text { Os ambientes da } \\
\text { UNICENTRO, } \\
\text { especialmente os de } \\
\text { trabalho, são salubres? }\end{array}$ & São & $\begin{array}{l}\text { O ambiente de trabalho } \\
\text { deve ser ventilado e com } \\
\text { uma boa luminosidade. }\end{array}$ & $\begin{array}{c}\text { “Os ambientes da } \\
\text { UNICENTRO são ventilados } \\
\text { e claros. Está sendo feito } \\
\text { um mapeamento de risco } \\
\text { para mostrar as condições } \\
\text { de trabalho. Falta dentro } \\
\text { da Universidade um espaço } \\
\text { para que o docente possa } \\
\text { desenvolver, preparar suas } \\
\text { aulas, desta forma não fixa o } \\
\text { docente na Universidade”. }\end{array}$ \\
\hline
\end{tabular}

Fonte: Pesquisa de Campo (2013).

Conforme o que foi dito pelo participante da pesquisa, o ambiente laboral da instituição atende aos requisitos necessários para conferir mobilidade, bem-estar e salubridade aos servidores. No caso da Ergonomia, essa condição atende aos requisitos legais instituídos em favor dos trabalhadores, os quais intentam garantir condições mínimas para que os servidores possam exercer suas atividades com segurança, minimizando os riscos de acidentes e de comprometimento à saúde dos servidores.

A Constituição Federal (BRASIL, 1988) prevê que a dignidade do trabalhador deve ser respeitada e preservada pelas organizações, sendo as condições ambientais de trabalho adequadas determinantes para que tenha assegurada uma qualidade de vida que seja digna e compatível com seus anseios e necessidades.

O DIRETOR B realçou que, no caso da Ergonomia, ainda estão sendo feitos mapeamentos acerca da situação existente nos setores que compõem a instituição, visando a futuras adaptações, ainda que ressalte que as mudanças não ocorrem de forma célere. Contudo, a realização do mapeamento denota a preocupação dos gestores da instituição com a saúde e o bem-estar dos servidores, aspecto positivo quando se considera a influência que o ambiente de trabalho exerce sobre o ser humano. 
Rocha (2012) aponta que a QVT, no tocante ao ambiente de trabalho, demanda um acompanhamento constante, para que sejam efetivadas as mudanças que garantam ao servidor a condição de exercer sua função de forma plena, ou seja, com os riscos mitigados e com um Meio Ambiente que não influencie negativamente na sua saúde.

A Sustentabilidade enfoca o bem-estar do ser humano, tendo a QVT como um referencial significativo para a constituição de um ambiente laboral compatível com as necessidades e anseios dos servidores, sendo que, no caso da Instituição de Ensino Superior, sua forma de atuação pode servir como exemplo para as demais organizações, atendendo sua função educativa e de compromisso em repassar para a comunidade exemplos bem-sucedidos de gestão organizacional.

ATENÇÃo À SAÚDE

Em relação à atenção à saúde do servidor na instituição, o DIRETOR B relatou: Quadro 2 - Atenção à saúde do servidor na UNICENTRO

\begin{tabular}{|c|c|c|c|}
\hline QUESTÃO & $\begin{array}{l}\text { CONDIÇÃO } \\
\text { EXISTENTE }\end{array}$ & MOTIVO & $\begin{array}{c}\text { CONSIDERAÇÕES DO } \\
\text { DIRETOR B }\end{array}$ \\
\hline $\begin{array}{l}\text { A UNICENTRO oferece } \\
\text { atividades de ginástica } \\
\text { laboral ou atividades } \\
\text { semelhantes aos seus } \\
\text { servidores e bolsistas? }\end{array}$ & Não oferece & $\begin{array}{l}\text { No momento não existe. } \\
\text { Está nascendo um } \\
\text { projeto chamado Serviço } \\
\text { de Atenção à Saúde do } \\
\text { Servidor (SASU) da } \\
\text { UNICENTRO. }\end{array}$ & $\begin{array}{l}\text { "Este projeto terá um rol } \\
\text { de ações voltadas à saúde } \\
\text { do trabalhador, com várias } \\
\text { frentes: da promoção, da } \\
\text { prevenção e da educação da } \\
\text { saúde". }\end{array}$ \\
\hline \begin{tabular}{|l|} 
A UNICENTRO possui \\
grupo especializado e/ou \\
capacitado para apoio às \\
neuroses (antitabagismo, \\
alcoolismo, drogas e \\
neuroses diversas)? \\
\end{tabular} & Não possui & $\begin{array}{c}\text { Não há profissionais } \\
\text { como: Enfermeiro, } \\
\text { Médico do Trabalho, } \\
\text { Psicólogos, Assistentes } \\
\text { Sociais no quadro para } \\
\text { isso. } \\
\end{array}$ & $\begin{array}{l}\text { "Ações de prevenção e } \\
\text { conscientização estão } \\
\text { previstas no SASU". }\end{array}$ \\
\hline $\begin{array}{l}\text { A UNICENTRO possui } \\
\text { programa de saúde } \\
\text { ocupacional? }\end{array}$ & Possui & $\begin{array}{l}\text { Sentindo a necessidade, } \\
\text { está sendo criado o SASU }\end{array}$ & $\begin{array}{c}\text { "Existe dificuldade } \\
\text { financeira nesse sentido, } \\
\text { nós não temos médico do } \\
\text { trabalho. O SASU não } \\
\text { é o PCMSO (Plano de } \\
\text { Controle Médico a Saúde } \\
\text { Ocupacional)". }\end{array}$ \\
\hline $\begin{array}{l}\text { A UNICENTRO possui } \\
\text { programa de orientação } \\
\text { nutricional? }\end{array}$ & Possui & $\begin{array}{l}\text { Verificando também } \\
\text { a importância da } \\
\text { orientação nutricional, } \\
\text { a Universidade possui } \\
\text { o ambulatório de } \\
\text { Nutrição disponível e em } \\
\text { funcionamento. }\end{array}$ & $\begin{array}{l}\text { “A ideia é de que as ações } \\
\text { de Nutrição vão integrar o } \\
\text { SASU”. }\end{array}$ \\
\hline
\end{tabular}

Fonte: Pesquisa de Campo (2013).

A atenção à saúde do trabalhador é um dos principais referenciais do QVT, pois o ambiente laboral não pode, em nenhuma circunstância, comprometer a integridade física e mental do servidor, cabendo à Universidade tomar as medidas necessárias para que os riscos ao seu bemestar sejam reduzidos.

Contudo, conforme indicam Engelman, Guisso e Fracasso (2009), a atenção à saúde não pode se pautar no interesse da instituição em manter seu servidor apto ao exercício da sua função, mas sim como uma forma de respeitar sua dignidade e de estabelecer um compromisso maior com seu bem-estar. 
Considerando as informações repassadas pelo DIRETOR B, a UNICENTRO necessita rever sua gestão de recursos humanos, pois não está atenta para fatores previstos na A3P, os quais conferem maior segurança e bem-estar ao servidor. Essa situação se confirma a partir da constatação de que não há, ainda, um projeto implantado para a saúde do servidor. Nesse cenário, o planejamento na área de saúde não consegue atentar adequadamente para o desenvolvimento de ações que influenciem no bem-estar do trabalhador, sendo um exemplo a ginástica laboral, pois proporciona maior qualidade de vida no seu cotidiano, reduzindo os riscos de lesões e de algumas doenças ocupacionais.

Outra lacuna apontada pelo DOCENTE B refere-se a de apoio para os servidores que apresentem alguma neurose, realçando que a falta de um programa elaborado e efetivamente aplicado na instituição ocasiona sérios prejuízos ao trabalhador, sobretudo na ausência de práticas que poderiam contribuir para o exercício de suas funções. Nessa direção, Sampaio e Oliveira (2008, p. 72) indicam que investir na qualidade de vida voltada aos funcionários nas instituições “ $[\ldots]$ se constitui hoje uma das principais ações para a prevenção de problemas oriundos do exercício laboral que, em condições inadequadas, podem ocasionar, pelo excessivo ritmo de trabalho, grandes males à saúde dos trabalhadores".

Na UNICENTRO, que oferta cursos que podem preparar abordagens específicas em relação à QVT, como Enfermagem e Educação Física, a alegação de que essa possibilidade envolveria custos significativos não se justifica, posto que há profissionais qualificados para estabelecer desde programas de ginástica laboral, como os professores de Educação Física; como também a atenção inicial às neuroses, efetivadas pelos enfermeiros.

Não há como uma instituição exercer sua Responsabilidade Ambiental de forma plena quando não dá a devida atenção para o ser humano na sua estrutura organizacional. Especialmente no tocante à saúde, que é o fator que mais interfere, não só no bem-estar do servidor, mas também na sua produtividade. A falta da devida atenção possibilita risco maior de comprometimento à sua qualidade de vida.

Nesse contexto, a A3P inclui a temática da QVT, reforçando que a noção de Sustentabilidade nas instituições públicas não se limita à temática ambiental, mas contempla o respeito à dignidade do ser humano que, em essência, é o principal articulador das ações desenvolvidas pelas organizações no tocante à preservação do Meio Ambiente.

\section{DESENVOLVIMENTO/CAPACITAÇÃO}

Em relação às ações de desenvolvimento/capacitação dos servidores, o DIRETOR B informa:

Quadro 3 - Desenvolvimento/capacitação dos servidores da UNICENTRO

\begin{tabular}{|l|c|c|c|}
\hline QUESTÃO & $\begin{array}{c}\text { CONDIÇÃO } \\
\text { EXISTENTE }\end{array}$ & MOTIVO & $\begin{array}{c}\text { CONSIDERAÇÕES DO } \\
\text { DIRETOR B }\end{array}$ \\
\hline
\end{tabular}




\begin{tabular}{|c|c|c|c|}
\hline $\begin{array}{l}\text { A UNICENTRO incentiva } \\
\text { o desenvolvimento e a } \\
\text { capacitação de seus servidores } \\
\text { por meio da autonomia } \\
\text { das atividades a serem } \\
\text { desenvolvidas? }\end{array}$ & Incentiva & $\begin{array}{c}\text { Existe uma preocupação } \\
\text { constante com a capacitação } \\
\text { dos servidores da } \\
\text { Universidade, pois isso } \\
\text { traz crescimento pessoal e } \\
\text { profissional para os servidores } \\
\text { e proporciona também ganhos } \\
\text { na qualidade para a instituição. }\end{array}$ & \begin{tabular}{|c|} 
"Atualmente existe uma série \\
de iniciativas de capacitação \\
do servidor: oficinas, cursos \\
pontuais, afastamento parcial e \\
integral para capacitação. Nos \\
últimos anos foram ofertados \\
vários cursos (orçamento \\
corporativo, projetos e \\
convênios, Contabilidade \\
Pública, etc.)".
\end{tabular} \\
\hline $\begin{array}{l}\text { A UNICENTRO incentiva } \\
\text { o desenvolvimento e a } \\
\text { capacitação de seus servidores } \\
\text { por meio do aproveitamento } \\
\text { das habilidades individuais e } \\
\text { coletivas? }\end{array}$ & Incentiva & $\begin{array}{l}\text { Considera-se importante este } \\
\text { incentivo, pois esta iniciativa } \\
\text { traz contentamento ao } \\
\text { servidor e para a equipe onde } \\
\text { (sic) ele atua. }\end{array}$ & \begin{tabular}{|} 
"Infelizmente, hoje, não existe \\
dentro da Universidade um \\
mapeamento do servidor com \\
relação às suas habilidades e \\
competências, fazendo a sua \\
locação no setor, no serviço e na \\
função certa. Não faz sentido, \\
enquanto a Universidade, \\
com apenas 240 funcionários \\
efetivos, na conjuntura atual \\
isto é impossível".
\end{tabular} \\
\hline $\begin{array}{l}\text { A UNICENTRO incentiva } \\
\text { o desenvolvimento e a } \\
\text { capacitação de seus servidores } \\
\text { por meio da percepção do } \\
\text { significado do trabalho } \\
\text { individual e coletivo. }\end{array}$ & Incentiva & $\begin{array}{c}\text { Considera-se o ambiente } \\
\text { de trabalho e a importância } \\
\text { da capacitação, sendo } \\
\text { fundamental para o } \\
\text { desenvolvimento das } \\
\text { atividades da Universidade. }\end{array}$ & $\begin{array}{l}\text { "Percebe-se que o corpo de } \\
\text { funcionários é mais coeso do } \\
\text { que dos docentes. Pode ser } \\
\text { considerada a independência } \\
\text { dos docentes". }\end{array}$ \\
\hline
\end{tabular}

Fonte: Pesquisa de Campo (2013).

O desenvolvimento/capacitação dos servidores é de grande relevância para sua qualificação, especialmente porque atenta, também, para a aquisição de habilidades e competências que influenciarão na qualidade do exercício funcional efetivado. Como medida educativa, o desenvolvimento/capacitação permite ao servidor desenvolver habilidades e capacidades que podem ser de grande valia ao cotidiano da organização, como também para ele assimilar novos saberes que são fundamentais para posicionar-se diante das propostas da instituição, como as que envolvem as ações relativas ao A3P.

Dias (2001)identifica que os servidores públicos necessitam de constante desenvolvimento/ capacitação para terem uma aquisição contínua de saberes que influenciarão na sua atuação laboral, como também de possibilidades para que tenha melhores condições, tanto para assimilar como de executar as propostas administrativas/operacionais da instituição. Esta se torna relevante quando se pensa em Sustentabilidade, pelo fato de propor uma nova postura gerencial, que demanda maior envolvimento dos servidores para atingirem as metas e os objetivos propostos.

O DIRETOR B pontuou que a instituição de Ensino Superior está atenta no sentido de oportunizar o desenvolvimento/capacitação de seus servidores, ainda que haja uma lacuna, na instituição, em relação ao mapeamento das habilidades e das capacidades dos servidores Ele concorda que os indicadores podem servir para a disponibilização de cursos e capacitações compatíveis com as necessidades e as potencialidades existentes na instituição.

A concepção de desenvolvimento/capacitação dos servidores necessita contemplar a problemática ambiental, pelo fato de ela ser relevante para a instituição em toda sua estrutura organizacional, segundo Marcomim e Silva (2009, p. 113):

[…] pessoas portadoras de uma sensibilidade particular para as questões ambientais ou, na pior hipótese, que percebam claramente os diversos elementos 
em causa; ou, na ausência provisória desse conhecimento, que pelo menos não façam oposição.

O desenvolvimento/capacitação, numa Universidade, pode se constituir em um elemento que oportuniza aos servidores a condição de refletirem acerca da temática ambiental, no sentido de incorporarem, de forma consciente, as medidas definidas pelos gestores, visando contribuir para a abordagem da preservação ambiental no âmbito da Sustentabilidade.

O DIRETOR B, devido ao cargo que exerce na instituição, foi responsável por responder as questões constantes no Protocolo de Krüguer et al. (2011) dos eixos Integração no Ambiente de Trabalho e Sensibilização e Capacitação dos servidores. No que se refere à integração ao ambiente de trabalho, o DIRETOR B indicou:

Quadro 22 - Integração no ambiente do trabalho do servidor da UNICENTRO

\begin{tabular}{|c|c|c|c|}
\hline QUESTÃO & $\begin{array}{l}\text { CONDIÇÃO } \\
\text { EXISTENTE }\end{array}$ & MOTIVO & $\begin{array}{c}\text { CONSIDERAÇÕES DO } \\
\text { DIRETOR B }\end{array}$ \\
\hline $\begin{array}{l}\text { A UNICENTRO possui } \\
\text { controle da jornada de } \\
\text { trabalho? }\end{array}$ & Possui & $\begin{array}{l}\text { A jornada de trabalho deve ser } \\
\text { respeitada (jornada de } 8 \text { horas } \\
\text { diárias e } 40 \text { horas semanais) }\end{array}$ & $\begin{array}{c}\text { "O que se percebe atualmente } \\
\text { é a sobrecarga dos servidores, } \\
\text { carência de servidores, tanto } \\
\text { de funcionários quanto de } \\
\text { professores". }\end{array}$ \\
\hline $\begin{array}{l}\text { A UNICENTRO incentiva e } \\
\text { promove a integração social } \\
\text { interna e externa por meio da } \\
\text { ausência de preconceitos? }\end{array}$ & Incentiva & $\begin{array}{l}\text { A instituição promove debates } \\
\text { à integração e de maneira } \\
\text { sempre legal e sempre } \\
\text { respeitada. }\end{array}$ & $\begin{array}{c}\text { “Os concursos preveem } \\
\text { a inclusão das minorias, } \\
\text { inclusão do deficiente, do } \\
\text { afrodescendente, cotas para } \\
\text { alunos carentes, cotas para } \\
\text { alunos provenientes da rede } \\
\text { pública”. } \\
\end{array}$ \\
\hline $\begin{array}{l}\text { A UNICENTRO incentiva } \\
\text { e promove a integração } \\
\text { social interna por meio da } \\
\text { integração de servidores em } \\
\text { áreas comuns e eventos de } \\
\text { finalidade integrativa? }\end{array}$ & Não incentiva & $\begin{array}{l}\text { Não existem ações neste } \\
\text { sentido. }\end{array}$ & $\begin{array}{c}\text { "Existem apenas algumas } \\
\text { ações isoladas, mas que não } \\
\text { são da UNICENTRO, ações } \\
\text { de integração promovidas } \\
\text { institucionalmente. Exemplo: } \\
\text { festas de final de ano de } \\
\text { confraternização, realmente não } \\
\text { existem". } \\
\end{array}$ \\
\hline $\begin{array}{l}\text { A UNICENTRO incentiva e } \\
\text { promove a integração social } \\
\text { interna por meio do senso } \\
\text { comunitário? }\end{array}$ & Incentiva & $\begin{array}{l}\text { A universidade incentiva } \\
\text { sim e sabe da importância } \\
\text { desta integração para toda a } \\
\text { comunidade acadêmica. }\end{array}$ & \begin{tabular}{|} 
"Existe o SIEPE, que é \\
uma atividade de ensino, \\
pesquisa e extensão que \\
congrega a Universidade na \\
sua totalidade, integração \\
de docentes e servidores \\
empossados, integração das \\
chefias departamentais, integra \\
todos os alunos, docentes, \\
pesquisadores e extensionistas. \\
É uma grande atividade de \\
integração dos vários pilares da \\
Universidade (Ensino, Pesquisa \\
e Extensão)". \\
\end{tabular} \\
\hline
\end{tabular}




\begin{tabular}{|c|c|c|c|}
\hline $\begin{array}{l}\text { A UNICENTRO incentiva e } \\
\text { promove a integração social } \\
\text { interna por meio da promoção } \\
\text { dos relacionamentos } \\
\text { interpessoais? }\end{array}$ & Incentiva & $\begin{array}{c}\text { Sente sim a necessidade desta } \\
\text { integração e procura promover } \\
\text { na medida do possível. }\end{array}$ & $\begin{array}{l}\text { "A integração depende muito } \\
\text { da liderança de cada setor, seja } \\
\text { administrativo ou pedagógico. } \\
\text { A integração é macro, devendo } \\
\text { ser trabalhada junto às } \\
\text { chefias imediatas. Em 2013, } \\
\text { vários cursos foram ofertados } \\
\text { neste sentido. Exemplo: } \\
\text { Relacionamento interpessoal, } \\
\text { Mediação de conflitos, } \\
\text { Integração no ambiente de } \\
\text { trabalho e várias oficinas. A } \\
\text { participação do servidor é } \\
\text { opcional e não obrigatória”. }\end{array}$ \\
\hline $\begin{array}{l}\text { A UNICENTRO incentiva } \\
\text { e respeita a liberdade de } \\
\text { expressão? }\end{array}$ & Incentiva & $\begin{array}{c}\text { A Universidade tem o dever } \\
\text { de servir de exemplo nesta } \\
\text { questão. }\end{array}$ & $\begin{array}{l}\text { “Acontece de maneira muito } \\
\text { acentuada. A liberdade de } \\
\text { expressão, a liberdade de } \\
\text { recursos, a liberdade de opinião, } \\
\text { dentro da universidade, é } \\
\text { muito forte, e nem poderia } \\
\text { ser diferente. Os conselhos } \\
\text { superiores permitem que toda } \\
\text { a comunidade acadêmica possa } \\
\text { recorrer de qualquer coisa”. }\end{array}$ \\
\hline $\begin{array}{l}\text { A UNICENTRO incentiva } \\
\text { e respeita a privacidade } \\
\text { pessoal? }\end{array}$ & Incentiva & $\begin{array}{l}\text { A Universidade considera a } \\
\text { privacidade pessoal muito } \\
\text { importante. }\end{array}$ & $\begin{array}{l}\text { "Respeita e a comunidade } \\
\text { acadêmica não é exposta, não } \\
\text { tem sua privacidade ferida. O } \\
\text { que existe são pessoas que se } \\
\text { expõem (exemplo: facebook), } \\
\text { ficando a universidade sem } \\
\text { condições de interferir". }\end{array}$ \\
\hline $\begin{array}{l}\text { A UNICENTRO incentiva } \\
\text { e respeita o tratamento } \\
\text { impessoal? }\end{array}$ & Incentiva & $\begin{array}{c}\text { Sim. Todas as regras para } \\
\text { o tratamento de todas as } \\
\text { situações são estabelecidas em } \\
\text { regulamentos e em leis, pois } \\
\text { os regulamentos nos cercam, } \\
\text { mas ao mesmo tempo, nos } \\
\text { protegem. }\end{array}$ & $\begin{array}{c}\text { “A universidade é } \\
\text { absolutamente impessoal no } \\
\text { sentido da impessoalidade e da } \\
\text { legalidade da relação que uma } \\
\text { instituição pública tem que ter". }\end{array}$ \\
\hline
\end{tabular}

Fonte: Pesquisa de Campo (2013).

O DIRETOR B identificou, apenas, ausência de incentivo a eventos com finalidade integrativa. Há, porém, no ambiente da instituição, um respeito significativo a valores importantes nas relações humanas, como a privacidade e o direito de expressão, além de serem ofertados cursos como forma de contribuir na integração interna dos servidores.

A integração ao ambiente de trabalho é relevante para que a instituição consiga realizar a junção e a coesão de esforços em torno das ações, dos objetivos e das metas propostas, fator valorizado no âmbito da gestão pautada pela Sustentabilidade.

Schneider (2013) relata que o ser humano, na gestão sustentável, passa a ter destacadas suas capacidades e seus valores, fazendo com que se sinta plenamente inserido no ambiente de trabalho, podendo ter um maior comprometimento com as propostas de ações indicadas pela instituição.

A integração do Meio Ambiente ao trabalho permite que os servidores tenham uma noção mais significativa do impacto das ações previstas na estrutura organizacional e tenham condições 
de contribuir para que as medidas previstas em uma Agenda Ambiental, por exemplo, possam ser concretizadas e surtam os efeitos esperados.

A condição da instituição, apresentada pelo DIRETOR B, denota a intenção de promover uma interação ambiental laboral mais significativa, sendo feitos esforços visando à aproximação entre os servidores, ao mesmo tempo em que há espaço para que, individualmente, possam se manifestar e realçar suas percepções pessoais a respeito da Universidade.

O programa SIEPE, por exemplo, oportunizada uma integração maior no ambiente universitário, fazendo com que a instituição se torne um espaço de interações, em busca de alternativas diante das situações que são vivenciadas tanto pela universidade como também pela comunidade acadêmica.

Nesse contexto, a implantação de uma Agenda Ambiental encontra espaço para ser amplamente debatida, como também integrada às condições existentes na instituição. Isso contribui para que as medidas adotadas estejam coerentes com as noções de Sustentabilidade que embasam a gestão, a partir do momento em que a entidade se compromete com uma Agenda dessa natureza.

\section{SINTETIZANDO OS RESULTADOS:}

De acordo com o que foi revelado pelos participantes da pesquisa por meio do protocolo elaborado por Krüger et al. (2011), foi constatado que no eixo 3 (qualidade de vida no ambiente de trabalho), das dezoito ações previstas, 84\% são contemplados pela UNICENTRO;

Observando os percentuais alcançados, a UNICENTRO, na média, alcança o percentual de 67,4\% das ações propostas pela A3P e destacadas no protocolo de Krüger et al. (2011). Porém, mesmo sendo um percentual significativo, é necessário considerar que, no caso do eixo 3, o atendimento à maioria das ações é a constituição de um ambiente que favoreça o desempenho funcional do servidor e o atendimento à legislação trabalhista que, caso não fossem observadas, gerariam sanções legais à Universidade.

\section{CONSIDERAÇÕES FINAIS}

A contribuição da UNICENTRO no tocante à conscientização ainda não ocorre de forma plena, porque a A3P não foi implantada na sua estrutura organizacional. A inexistência de uma Agenda Ambiental mais efetiva faz com que as ações e as medidas no tocante à Sustentabilidade e ao exercício da responsabilidade socioambiental sejam isoladas.

Nesse sentido, baseado nas respostas obtidas durante a pesquisa, é possível afirmar que existem condições institucionais na UNICENTRO para desenvolver a A3P no seu processo de gestão. Essa perspectiva decorre do fato de que a maioria dos itens relacionados aos eixos da Agenda podem ser implantados na sua estrutura organizacional.

Portanto, torna-se premente que a universidade modifique essa situação, como forma de estabelecer um gerenciamento pautado na Sustentabilidade, exercendo com maior sentido a sua responsabilidade ambiental, além de atender à dimensão educativa que se espera de uma universidade, pois seu modo de atuação serve de exemplo para as demais instituições da sociedade, além de contribuir de maneira relevante com a causa ambiental.

Lima, A.C.P; Golembiewsk, C. 
A ausência da A3P na UNICENTRO é consequência da falta de uma política ambiental estruturada, isto significa que as medidas e as ações envolvendo a Sustentabilidade têm um alcance limitado. A limitação é entendida como uma decorrência da ausência de uma política ambiental, pois não há a intenção de estabelecer uma postura gerencial focada em ações sustentáveis, apenas a realização de medidas que são comumente empregadas pelas organizações, visando ao uso mais criterioso dos recursos naturais.

As ações envolvendo o uso de recursos naturais, comoágua ou energia elétrica, são desenvolvidas na instituição dentro de uma perspectiva de economia, não abrangendo uma conscientização maior acerca da importância dessas medidas no contexto da Responsabilidade Ambiental.

Em relação aos eixos temáticos, existem ações desenvolvidas pela UNICENTRO que estão previstas na $\mathrm{A} 3 \mathrm{P}$, revelando que suas diretrizes e propostas são passíveis de serem executadas. Dessa forma, assegura-se mais destaque para aspectos como a atenção ao uso dos recursos naturais, ainda que não haja um objetivo mais claro com a causa ambiental.

Outro ponto atendido pela universidade refere-se à atenção aos servidores, seja na questão da qualidade de vida, seja na perspectiva de sensibilização e capacitação. Essas atividades ocorrem em função da necessidade de qualificação profissional e também para atender às diretrizes impostas pela legislação trabalhista brasileira.

$\mathrm{Na}$ instituição, a motivação econômica acaba surgindo como a principal razão para a execução das medidas, sendo a contribuição à preservação do Meio Ambiente uma decorrência natural. $\mathrm{O}$ que de preocupante se evidencia é a ausência de uma percepção mais abrangente na comunidade acadêmica acerca dos esforços que a universidade ainda pode fazer, visando contribuir para minimizar o impacto ambiental de suas ações.

Entre as situações destacadas acerca dos eixos da A3P, a questão da sensibilização merece uma atenção maior, no sentido de conferir um nível também mais elevado de consciência sobre o significado das ações realizadas que colaboram com o Meio Ambiente, para que sejam assimiladas e possam ser praticadas também fora do ambiente de trabalho.

Por fim, existem condições de implantação da A3P na UNICENTRO, sendo necessária, conforme foi possível constatar a partir da aplicação do protocolo de Kruguer et al. (2011), a definição de uma política ambiental que fortaleceria as intenções da universidade em atuar, tanto na dimensão operacional como na dimensão administrativa, de forma sustentável, contribuindo mais significativamente para a problemática ambiental.

\section{REFERÊNCIAS}

BRASIL. Constituição da República Federativa do Brasil de 1988. Diário Oficial, Brasília, 1988.

BRASIL. Ministério do Meio Ambiente. O que é a A3P? Disponível em: < http://www.mma.gov.br/ responsabilidade-socioambiental/a3p>. Acesso em: 22 de maio 2013.

BRASIL. Ministério Público Federal. O que é A3P? Disponível em: http://pga.pgr.mpf.gov.br/pga/a3p. Acesso em: 15 de maio 2013.

CAMPOS, Augusto. Agenda ambiental: como fazer. Disponível em: <http://www.efetividade. net/2010/02/agenda-ambiental-como-fazer.html> Acesso em 22 de mai. 2013. 
ENGELMAN, Raquel; GUISSO, Rubia Marcondes; FRACASSO, Edi Madalena. Ações de gestão ambiental nas instituições de ensino superior: o que tem sido feito? Revista de Gestão Social e Ambiental, v. 3, n. 1, p. 22-33, janeiro/abril 2009.

FERREIRA, Maria Augusta Soares de Oliveira. Apontamentos sobre a gestão socioambiental na administração pública brasileira. In.: BLIACHERIS, Marcos Weiss; FERREIRA, Maria Augusta Soares de Oliveira. Sustentabilidade na Administração Pública: Valores e Práticas de Gestão Socioambiental. Belo Horizonte: Fórum, 2012.

GOLDONI, Lílian Rosana. Princípios ambientais: prevenção e precaução. Disponível em: <http:// www.clubjus.com.br/?artigos\&ver=2.10103> Acesso em 20 mai. 2013.

KRUGER, Silvana Dalmutt; FREITAS, Claudio Luiz de; PFITSCHER, Elisete Dahmer; PETRI, Sérgio Murilo. Gestão ambiental em instituição de ensino superior - uma análise da aderência de uma instituição de ensino superior comunitária aos objetivos da Agenda Ambiental na Administração Pública (A3P). Revista Gual, Florianópolis, v. 4, n. 3, p. 44-62, setembro/dezembro de 2011.

MACHADO, Jacimara Guerra. Gestão ambiental na administração pública: a mudança de padrões de consumo começa em casa. Brasília: UNB, 2012.

MARCOMIN, Fátima Elizabeti; SILVA, Alberto Dias Vieira. A sustentabilidade no ensino superior brasileiro: alguns elementos a partir da prática de educação ambiental na universidade. Contrapontos, v. 9, n. 2, p. 104-117, maio/agosto de 2009.

OLIVEIRA, Rodrigo Ribeiro de; CASTRO, Dagmar Silva Pinto de; LIMONGI-FRANÇA, Ana Cristina; PEREIRA, Jairo; OLIVEIRA, Gracieli de Miranda. Um estudo sobre as relações existentes de qualidade de vida no trabalho e responsabilidade social empresarial. Disponível em: http://www. aedb.br/seget/artigos09/528_QVT_e_RSE.pdf. Acesso em: abril de 2014.

ROCHA, Elizabeth Porta Nova Mendes Ribeiro da. Programas de qualidade de vida no serviço público. In.: BLIACHERIS, Marcos Weiss; FERREIRA, Maria Augusta Soares de Oliveira. Sustentabilidade na Administração Pública: Valores e Práticas de Gestão Socioambiental. Belo Horizonte: Fórum, 2012.

SAMPAIO, Adelar Aparecido; OLIVEIRA, João Ricardo Gabriel. A ginástica laboral na promoção da saúde e melhoria da qualidade de vida no trabalho. Caderno de Educação Física, v. 7, n. 13, p. 71-79, $2^{\circ}$ semestre de 2008 .

SCHNEIDER, Evânia. Gestão ambiental municipal: preservação ambiental e desenvolvimento sustentável. Disponível em: <http://www.portalga.ea.ufrgs.br/acervo

/ds_art_05.pdf>. Acesso em: 22 de maio 2013.

SILVA, Luis Celso; LONGO, Orlando Celso; QUELHAS, Osvaldo Luiz Gonçalves. Qualidade de vida no trabalho no contexto da sustentabilidade: uma estrutura conceitual a partir da revisão de literatura.

INGEPRO - Inovação, Gestão e Produção, v. 02, n. 01, p. 75-84, 2010.

SUA PESQUISA, portal de pesquisas temáticas. Responsabilidade Ambiental. Disponível em: <http:// www.suapesquisa.com/ecologiasaude/Responsabilidade_ambi

ental.htm>. Acesso em: abril de 2014.

VAZ, Caroline Rodrigues; FAGUNDES, Alexandre Borges; OLIVEIRA, Ivanir Luiz; KOVALESKI, João Luiz; SELIG, Paulo Maurício. Sistema de gestão ambiental em instituição de Ensino Superior: uma revisão. GEPROS, n. 3, p. 45-58, julho/setembro de 2010. 